\title{
Oxytocin Measurement
}

National Cancer Institute

\section{Source}

National Cancer Institute. Oxytocin Measurement. NCI Thesaurus. Code C74869.

The determination of the amount of oxytocin hormone present in a sample. 